\title{
Sero-prevalence of leptospirosis among presumptive malaria patients in a secondary health facility in Oyo state, Southwest Nigeria
}

Mathias Ayuk Besong ( $\nabla$ drbisong@yahoo.com )

Field Epidemiology Training Program https://orcid.org/0000-0002-8947-5736

Emmanuel Awosanya

University of Ibadan

Olusoji Adeyanju

Adeoyo Maternity Teaching Hospital, Yemetu, Ibadan

A. Adedayo Adigun

Adeoyo Maternity Teaching Hospital, Yemetu, Ibadan

Charles Akatobi Micchael

African Field Epidemiology Network

Muhammed Shakir Balogun

African Field Epidemiology Network

Gabriel Ogundipe

University of Ibadan

Research

Keywords: seroprevalence, Leptospirosis, RDT, Malaria, Nigeria

Posted Date: February 25th, 2020

DOI: https://doi.org/10.21203/rs.2.24521/v1

License: (9) (i) This work is licensed under a Creative Commons Attribution 4.0 International License.

Read Full License 


\section{Abstract}

Background: Leptospirosis is a neglected tropical zoonoses that presents with fever and can be misdiagnosed, with fatal outcomes. Its incidence has been on the increase in recent times with 1 million cases and over 60,000 deaths reported annually worldwide. We determined the seroprevalence of leptospirosis and associated risk factors among presumptive malaria patients in a secondary health facility in Ibadan.

Methods: We used Leptospira Rapid Diagnostic Test kit to estimate the seroprevalence of leptospirosis among 143 patients who presented at the study center between $27^{\text {th }}$ April and $15^{\text {th }}$ May 2019 whom a physician had seen and tentatively diagnosed malaria. We used one drop of blood for the test from blood collected by trained laboratory technicians for malaria diagnosis. Data on patients' demographics and risk factors were collected using an interviewer-administered questionnaire. We calculated frequencies, means and proportion. We did bivariate analyses at $\mathrm{a}_{0.05}$ to test for associations.

Result: The median age of the participants was 34 years (range: 6 months-80 years). Eighty-nine (62.2\%) of them were females. Of the 143 tested, 12 (8.4\%) were positive for Leptospira IgM/lgG antibodies. Eleven $(7.7 \%)$ patients were positive for malaria. One $(0.7 \%)$ was positive for both malaria and leptospirosis. None of the risk factors measured was significantly associated with leptospirosis.

Conclusion: we confirmed Leptospirosis among febrile patients at the study center We found that the seroprevalence of leptospirosis is same as that of malaria among the sampled population. However, leptospirosis/malaria co-infection was low. We recommend a review of the diagnostic protocol to include leptospirosis as a differential.

\section{Introduction}

Leptospirosis is one of the most important and most widespread emerging or re-emerging zoonotic diseases that has a considerable impact on human health with multiple outbreaks reported in all continents[1],2]. They report annually about 1 million cases with over 60,000 deaths, most of which occur in tropical and sub-tropical climates[1]. This is a huge leap considering that in Malaysia, for example, in 2004 they reported only 248 cases of leptospirosis cases compared to over 3,600 in 2012. This increase was because of changes in surveillance and diagnostic practices after introducing leptospirosis as a notifiable disease in 2010[3]. Thus supporting the fact that there is a possibility of gross under reporting of the disease, especially in resource-limited settings where there is usually poor awareness of the disease, and lack of adequate diagnostic facilities $[4,5]$. Spread of Leptospira organism to humans occur mainly by direct contact with an infected animal or indirectly through contact with contaminated soil or water through mucous membranes or broken skin[6,7]. Researchers relate spread of the disease to increased rainfall, livestock holding, increase rodent activities, poor hygiene practices, inadequate refuse disposal practices and overcrowding, conditions characteristic of urban slums in the developing world[8]. Leptospirosis is endemic in both wild and domestic animals in Africa. It is a major cause of febrile illness 
with about 750,000 new cases reported annually from various parts of the continent. However, most of them directly result from high urban growth rates and indiscriminate spread of shantytowns, especially around the flood-prone areas along the Atlantic coast[9]. In sub-Saharan Africa, the increasing prevalence is because of a combination of climate change, increasing risk of flooding, population growth, and urbanization $^{5}$. The prevalence of leptospirosis among febrile patients in Nigeria is poorly documented[9]. However, previous studies in "healthy" humans in some parts of the country puts it at between 13.5 and $20.4 \%[10,11]$. The common clinical signs/symptoms of the disease are fever, headache, myalgia, conjunctivitis, nausea, vomiting, diarrhea, abdominal pain, cough and sometimes skin rashes[12, 1]. The disease even in mild forms can cause foetal complications, including foetal deaths or abortion[13,[14]. The above signs and symptoms mimic many common diseases (malaria, typhoid fever, hepatitis B, cholera) but malaria is the usual presumptive diagnosis among febrile patients in many African settings[15]. There is therefore, a high probability of misdiagnosis and under-diagnosis of leptospirosis, sometimes with fatal outcomes. The aim of this study was, therefore, to determine the seroprevalence of leptospirosis among patients who present with fever at a secondary health facility in Ibadan, Oyo State, Southwest, Nigeria.

\section{Materials And Methods}

We conducted the study among febrile patients seeking medical care at the Out-Patients Department (OPD) of Adeoyo Maternity Teaching Hospital (AMTH), Yemetu, Oyo State between $27^{\text {th }}$ April and $15^{\text {th }}$ May 2019, whom a physician had seen and had made a presumptive diagnosis of malaria. AMTH is located in Ibadan North Local Government Area (LGA). The health facility is surrounded by classical urban slums, characterized by high rodent activities, poor hygiene practices, inadequate refuse disposal practices and overcrowding. The surrounding areas are also prone to flooding from blockage of drainages and the activities of the great Ogunpa river. The hospital receives patients from all social classes but mainly people of lower income level because of the highly subsidized treatment fees from the state government.

The study is a cross-sectional study with patients recruited consecutively. We included all patients with history of fever that has lasted at least 24-48 hours with or without headache, malaise, abdominal pain, vomiting, jaundice, whom a clinician has examined and referred to the laboratory for malaria test but had taken no prior medication for the current illness. We excluded those without fever and those with fever but were either on conventional treatment or not referred for malaria test from the study.

We calculated a sample of 143 participants using the formula for estimation of proportions at a prevalence of $10 \%[9] . Z_{a}=1.96, d=0.05$.

We collected one drop of blood aseptically from the blood already collected by trained laboratory technicians for the prescribed malaria test. We tested the collected drop of blood for leptospirosis using a rapid diagnostic test (RDT) kit for Leptospira IgM/lgG manufactured by AllTest $\mathrm{Co}^{\circledR}$. China with a relative 
sensitivity of $93.8 \%(95 \% \mathrm{Cl}$ : $69.8 \%$ - 99.8\%) and relative specificity of $98.7 \%$ (95\% Cl*: $96.1 \%-99.7 \%)$. Accuracy: $98.3 \%(95 \% \mathrm{Cl} * 95.8 \%-99.5 \%)$.

We collected patient's demographic information and information on associated factors such as occupation, level of education, presence of rats in the household, having a garden, and living in a flood prone area and the outcome variable using a pretested interviewer-administered structured questionnaire. We entered and coded all data in Microsoft Excel 2016. Data analysis was done using Epilnfo Software version 7.2.2 ${ }^{\circledR}$. The main outcome variable was the presence or absence of Leptospira antibodies (either IgG or IgM or both). We coded questionnaire data and results got from the RDT as dichotomous variables for bivariate analysis. We summarized data using frequencies, proportions and median and interquartile range. Bivariate analysis was used to explore the association between each of the potential risk factors and the outcome variable. Level of significance was set at $a_{0.05}$.

Ethical approval was obtained from the UI/UCH ethics committee (UI/EC/19/0207). Approval to work at the hospital was gotten from Oyo State Hospital Management board (OYSHMB/185 VOL IV/159). We also got verbal consent from participants.

\section{Results}

The median age of the respondents was 34 years (range: 6 months to 80 years). Eighty-nine (62.2\%) of the participants were females, while $91(63.6 \%)$ were unemployed. Most of the participants $(62.2 \%)$ had at least a secondary education or higher, with a similar proportion (63.3\%) being married (Table1).

Of the 143 samples tested, 12 (8.4\%) were positive for leptospiral IgG/ IgM. Eleven of these 12 samples were IgM positive. Eleven (7.7\%) of the samples tested positive for malaria while $1(0.7 \%)$ was positive for both Leptospira and Malaria (Table 3).

Among the febrile patients, 60 (42\%) reported having headache,38 (26.6\%) had body pain, 35(24.5\%) complain of stomach aches, $11(7.7 \%)$ had vomited during illness and none had jaundice (Table 2). None of the factors assessed was significantly associated with having leptospirosis (Table 4).

Table 1: Sociodemographic characteristics of febrile patients $(n=143)$ presenting at Adeoyo Maternity Teaching Hospital, Ibadan May, 2019 


\begin{tabular}{lc}
\hline Variable & Frequency $(\%)$ \\
\hline $\begin{array}{l}\text { Age Group (years) } \\
<10\end{array}$ & $22(15.4)$ \\
\hline $10-20$ & $25(17.5)$ \\
\hline $21-30$ & $17(11.9)$ \\
\hline $31-40$ & $32(22.4)$ \\
\hline $41-50$ & $15(10.5)$ \\
\hline $51-60$ & $15(10.5)$ \\
\hline$>60$ & $17(11.9)$ \\
\hline Sex & $54(37.8)$ \\
\hline Male & $89(62.2$ \\
\hline Female & \\
\hline Marital Status & $52(36.4)$ \\
\hline Single & $91(63.6)$ \\
\hline Married & \\
\hline Employment status & $52(36.4)$ \\
\hline Employed & $91(63.6)$ \\
\hline Unemployed & \\
\hline Education level & $89(62.2)$ \\
\hline Secondary and above & $54(37.8)$ \\
\hline Primary and below & \\
\hline Occupation & $47(32.9)$ \\
\hline Student & $5(3.5)$ \\
\hline Civil servant & \\
\hline Teacher & \\
\hline Trader & \\
\hline Others & \\
\hline
\end{tabular}

Table 2: Distribution of signs/symptoms among febrile patients $(n=143)$ and proportion positive for Leptospira RDT (n=12), AMTH Ibadan May, 2019

\section{Clinical features Frequency (\%) Proportion of Leptospira RDT-positive cases (\%)}

\begin{tabular}{lll}
\hline Fever & $143(100)$ & $12(100.0)$ \\
\hline Headache & $60(42)$ & $9(75.0)$ \\
\hline Myalgia & $38(26.6)$ & $4(33.3)$ \\
\hline Vomiting & $11(7.7)$ & $0(0.0)$ \\
\hline Abdominal Pain & $35(24.5)$ & $4(33.3)$ \\
\hline Jaundice & $0(0.0)$ & $0(0.0)$ \\
\hline
\end{tabular}

Table 3: Seroprevalence of Leptospirosis among febrile patients $(n=143)$ presenting at Adeoyo Maternity Teaching Hospital, Ibadan May, 2019 


\begin{tabular}{lcl}
\hline Test Result & Frequency & Percentage \\
\hline Leptospirosis & & \\
\hline
\end{tabular}

\begin{tabular}{ccc}
\hline IgM Positive & 11 & $\mathbf{7 . 7}$ \\
\hline IgG Positive & 1 & 0.7 \\
Co-infection with Malaria & 1 & 0.7 \\
\hline
\end{tabular}

Table 4: Bivariate analysis of factors associated with Leptospirosis among febrile patients presenting at Adeoyo Maternity Teaching Hospital, Ibadan May, $2019(n=143)$

\begin{tabular}{|c|c|c|c|c|}
\hline Variable & $\begin{array}{c}\text { Disease } \\
\text { Present } \\
\mathrm{n}=12 \\
\end{array}$ & $\begin{array}{c}\text { Disease absent } \\
n=131\end{array}$ & Odds Ratio & $95 \% \mathrm{CI}$ \\
\hline \multicolumn{5}{|l|}{ Sex } \\
\hline Male & 5 & 49 & 1.2 & $0.36-3.97$ \\
\hline Female & 7 & 82 & & \\
\hline \multicolumn{5}{|l|}{ Marital Status } \\
\hline Single & 3 & 49 & 0.6 & $0.14-2.16$ \\
\hline Married & 9 & 82 & & \\
\hline \multicolumn{5}{|l|}{ Educational Level } \\
\hline $\begin{array}{l}\text { Secondary/Post- } \\
\text { Secondary }\end{array}$ & 8 & 81 & 1.2 & $0.35-4.31$ \\
\hline Primary and below & 4 & 50 & & \\
\hline \multicolumn{5}{|l|}{ Employment Status } \\
\hline Employed & 6 & 85 & 1.8 & $0.56-1.6 .01$ \\
\hline Unemployed & 6 & 46 & & \\
\hline \multicolumn{5}{|l|}{ Keeping animals/Pets } \\
\hline Yes & 4 & 36 & 1.3 & $0.37-4.65$ \\
\hline No & 8 & 95 & & \\
\hline \multicolumn{5}{|l|}{ Own a backyard Garden } \\
\hline Yes & 5 & 21 & 3.7 & $1.01-12.92$ \\
\hline No & 7 & 110 & & \\
\hline \multicolumn{5}{|c|}{ Presence of Rodent in home } \\
\hline Yes & 11 & 120 & 1.0 & $0.12-8.57$ \\
\hline No & 1 & 11 & & \\
\hline \multicolumn{5}{|l|}{ Area prone to flooding } \\
\hline Yes & 3 & 15 & 2.6 & $0.63-10.59$ \\
\hline No & 9 & 116 & & \\
\hline \multicolumn{5}{|l|}{ Occupation } \\
\hline Trader & 7 & 54 & 2.0 & $0.60-6.62$ \\
\hline Others & 5 & 77 & & \\
\hline
\end{tabular}




\section{Discussion}

The results showed that the prevalence of leptospirosis among febrile patients presenting at the study center is $8.4 \%$. This is the same as the prevalence found among febrile patients in Tanzania[16] and falls within the range of the prevalence of other studies conducted on febrile patients in other parts of Africa: Egypt (4.0-19.8\%)[17,18], Kenya (3.2-17.9\%)[19], and Ghana (4.5-7.8\%)[20,21]. It is however much lower than the prevalence reported from the Terai region of Nepal [22]. The lower prevalence in our study could be as a result of the fact that we conducted our study between April and May when the rains were just starting as compared to the Nepal study, conducted during heavy rains and flooding [22]. Majority of the Leptospira-positive patients in this study were 25-40 years old. This is in harmony with findings from the Nepal study which also showed that persons in this age group are the active work force in the population, hence are more likely to get exposed during their various day-day jobs compared to others'[22,23]. Sixtysix percent of those that tested positive for the disease were female. This is the same as in the Nepal study, but very different from other studies which reported higher prevalence among males[24,23]. This high prevalence in females may be because females are more likely to get exposed while doing household jobs like cooking and waste disposal and other household activities that may expose them to contaminated water and food material. Also, in Ibadan, the practice of raising animals like sheep and goat is more common among women than men. The presence of Leptospira organism in farm animals in Nigeria is a well-documented fact, including in Ibadan'[1,25]. Many studies have shown leptospirosis to be a disease of the poor and less educated in society[22,9]. However, this study reported a different finding in which two third of patients that tested positive for leptospirosis had a minimum of tertiary education, with an average monthly salary of approximately 28,000 naira (USD 80 at USD $1=350$ naira), an amount above the national minimum wage of 17,000 naira (USD 49). The combination of good education and high incomes means these groups of people are more likely to have better health-seeking behaviour than the poor and less educated[26]. This observation is, however, not statistically significant. One patient, a 3-year-old male, tested positive for both malaria and leptospirosis. That he got infected at such a young age is not abnormal because studies have reported leptospirosis in younger children in rural areas in Vietnam, where the disease is endemic[27].

Study limitation: This is a pilot study with a relatively small sample size. We conducted the study in one facility and therefore we cannot extrapolat the results to the general population. We also conducted the study was also between April and May 2019 when the rainfall in Ibadan was not at its peak. Studies have shown that the prevalence of leptospirosis increases with an increase in rainfall and subsequent flooding $[22,28,1,29]$. However, we have shown from this study that not all febrile illnesses are malaria as assumed.

\section{Conclusions}

Leptospirosis was found among febrile patients seeking medical care at the study center. We also found that the seroprevalence of leptospirosis is same as that of malaria among the sampled population. 
However, the frequency of leptospirosis/malaria co-infection was low. Testing for leptospirosis is therefore recommend as a differential for febrile illnesses.

\section{Declarations}

Ethical approval and consent to participate: Ethical approval for this study was obtained from University of Ibadan/University College Hospital (UI/UCH) ethics committee with reference number UI/EC/19/0207. Approval to work at the hospital was gotten from Oyo State Hospital Management board (OYSHMB/185 VOL IV/159). Verbal consent was also obtained from participants.

Consent for publication: All authors have read and given consent for this manuscript to be published Availability of data and materials

The data analyzed for this study is available upon proper demand from the author Mathias Besong

\section{Competing interest}

The authors declare that they have no competing interest.

\section{Funding}

Not applicable

\section{Authors' contributions}

MB, conceived the study, EA, GO supervised the study, OA handled approvals for the study, MB, AA carried out the laboratory work, MB, EA data interpretation, $\mathrm{CM}$ reviewed manuscript

$\mathrm{MB}^{4}$ is guarantor of the paper. All authors read and approved final version of manuscript.

\section{Acknowledgement}

I thank the staff of the laboratory unit of Adeoyo Maternity Teaching Hospital, Yemetu, Ibadan for all the hard work they put in during the study period. I am also grateful to all the participants for accepting to take part in this study. Thank you to my mentors, Dr Chukwuma and Dr Bashorun for guiding me through this process. Finally, I wish to say a big thank you to my family for their continuous support.

\section{Authors information}

Dr. Mathias Ayuk Besong

Nigeria Field Epidemiology and Laboratory Training Program (NFELTP)

50 Haile Selassie Street, Asokoro, Abuja, Nigeria.drbisong@yahoo.com 


\section{Abbreviations}

AMTH: Adeoyo Maternity Teaching Hospital, RDT: Rapid Diagnosis Test, IgM: Immunoglobulin M, IgG: Immunoglobulin G,

\section{References}

1. de Vries SG, Visser BJ, Nagel IM, Goris MGA, Hartskeerl RA, Grobusch MP. Leptospirosis in SubSaharan Africa: A systematic review. Int J Infect Dis. 2014;28:e47-64.

2. Dobigny G, Gauthier P, Hou G, Choplin A, Durski KN, Bertherat E, et al. Leptospirosis and Extensive Urbanization in West Africa: A Neglected and Underestimated Threat? Urban Sci. 2018;2:1-7.

3. Benacer D, Thong KL, Verasahib K Bin, Galloway RL, Hartskeerl RA, Lewis JW, et al. Human Leptospirosis in Malaysia: Reviewing the Challenges after 8 Decades (1925-2012). Asia-Pacific Journal of Public Health. 2016.

4. Borja M. Burden of Disease Study: Leptospirosis in an Urban Setting, Metro Manila. http://www.upm.edu.ph/cph/LepconWeb/GroupB.htm (accessed on 12 May 2012).

5. Petti CA, Polage CR, Quinn TC, Ronald AR SM. Laboratory medicine in Africa: a barrier to effective health care. Clin Infect Dis. 2006;42:377-82.

6. World Health Organization. Human leptospirosis: guidance for diagnosis, surveillance and control. Int Leptospirosis Soc Geneva. 2003. http://whqlibdoc.who.int/hq/2003/WHO_CDS_CSR_EPH_2002.23.pdf).

7. Haake, D.A., Levett PN. Leptospirosis in humans. Curr Top Microbiol Immunol. 2015;387:65-97.

8. Maciel EA, de Carvalho AL, Nascimento SF, de Matos RB, Gouveia EL RM, Al. K. Household transmission of Leptospira infection in urban slum communities. PLoS Negl Trop Dis. 2008;2:e154.

9. Allan KJ, Biggs HM, Halliday JEB, Kazwala RR, Maro VP, Cleaveland S, et al. Epidemiology of Leptospirosis in Africa: A Systematic Review of a Neglected Zoonosis and a Paradigm for 'One Health' in Africa. PLoS Negl Trop Dis. 2015;9:1-25.

10. Agunloye CA, Alabi FO, Odemuyiwa SO OO. Leptospirosis in Nigerians: a seroepidemiological survey. Ind Vet J. 2001;78:371-5.

11. Onyemelukwe NF. A serological survey for leptospirosis in the Enugu area of eastern Nigeria among people at occupational risk. J Trop Med Hyg. 1993;96:301-4.

12. CDC Division of High-Consequence Pathogens and Pathology (DHCPP). World's Most Widespread Zoonotic Disease Poses New Risks -. Medscape. 2013.

13. Hartskeerl RA. Current tools and emerging technologies for leptospirosis diagnosis. 2015.

14. Centres for Disease Contron and Prevention. Leptospirosis Fact Sheet for Clinicians. CDC. 2018.

15. Brah S, Daou M, Salissou L, Mahaman S, Alhousseini D, B Al, et al. Fever of Unknown Origin in Africa: The Causes Are Often Determined! Heal Sci Dis. 2015;16:1-8. 
16. Biggs HM, Bui DM, Galloway RL, Stoddard RA, Shadomy SV, Morrissey AB et al. Leptospirosis among hospitalized febrile patients in northern Tanzania. Am J Trop Med Hyg. 2011;85:85(2):275-81.

17. Parker TM, Murray CK, Richards AL, Samir A, Ismail T, Fadeel MA et al. Concurrent infections in acute febrile illness patients in Egypt. Am J Trop Med Hyg. 2007;77:390-92.

18. Ismail TF, Wasfy MO, Abdul-Rahman B, Murray CK, Hospenthal DR, Abdel-Fadeel M et al. Retrospective serosurvey of leptospirosis among patients with acute febrile illness and hepatitis in Egypt. Am J Trop Med Hyg. 2006;75:1085-89.

19. Forrester AT, Kranendonk O, Turner LH, Wolff JW BH. Serological evidence of human leptospirosis in Kenya. East Afr Med J. 1969;46:497-506.

20. Tagoe JA, Puplampu N, Odoom SC, Abdul-Rahman B, Habashy EE, Pimentel B et al. Serosurvey of Leptospirosis among Patients with Acute Febrile Illness in Accra. Am J Trop Med Hyg. 2010;83:Suppl. S):306.

21. Hogerzeil HV, De Geus A, Terpstra WJ, Korver H LG. Leptospirosis in rural Ghana: Part 2. Current leptospirosis. Trop Geogr Med. 1986;38:408-14.

22. Regmi L, Pandey K, Malla M, Khanal S, Pandey BD. Sero-epidemiology study of leptospirosis in febrile patients from Terai region of Nepal. BMC Infect Dis. 2017;17:10-5.

23. Sethi S, Sharma N, Kakkar N, Taneja J, Chatterjee SS, Banga SS, et al. Increasing trends of leptospirosis in Northern India: A clinico-epidemiological study. PLoS Negl Trop Dis. 2010;4:1-7.

24. Panaphut T, Domrongkitchaiporn S, Thinkamrop B. Prognostic factors of death in leptospirosis: A prospective cohort study in Khon Kaen, Thailand. Int J Infect Dis. 2002;6:52-9.

25. Jagun AT, Ajayi OL, Ilugbo MO, Olugasa BO, Kafer J SH. Isolation and prevalence of pathogenic Leptospira interrogans in slaughtered cattle in two abattoirs in southwestern Nigeria. . Trib EU. 2011;1:235-7.

26. Adam V, Aigbokhaode A. Sociodemographic factors associated with the healthcare-seeking behavior of heads of households in a rural community in Southern Nigeria. Sahel Med J. 2018;21:31.

27. Thai KT, Nga TT, Phuong HL, Giao PT, Hung le Q, Binh TQ et al. Seroepidemiology and serological follow-up of anti-leptospiral IgG in children in Southern Vietnam. Acta Trop. 2008;106:128-31.

28. Costa F, Ribeiro GS, Felzemburgh RDM, Santos N, Reis RB, Santos AC, et al. Influence of Household Rat Infestation on Leptospira Transmission in the Urban Slum Environment. PLoS Negl Trop Dis. 2014;8.

29. Schneider MC, Velasco-hernandez J, Min K, Leonel DG, Baca-carrasco D, Gompper ME, et al. The Use of Chemoprophylaxis after Floods to Reduce the Occurrence and Impact of Leptospirosis Outbreaks. Int J Environ Res Public Heal. 2017;14:594. 